\title{
In Vitro Bioassay of Allelopathy in Robusta Coffee Callus Using Sandwich Method
}

\author{
Muchamad Imam Asrori ${ }^{1, *}$, Hamako Sasamoto ${ }^{2}$, Shinjiro Ogita ${ }^{3}$ \\ ${ }^{1}$ Program in Biological System Science, Graduate School of Comprehensive Scientific Research, Prefectural University \\ of Hiroshima Nanatsuka, Shobara, 727-0023, Japan \\ ${ }^{2}$ Tokyo University of Agriculture and Technology Fucyu, Tokyo, 183-8509, Japan \\ ${ }^{3}$ Departement of Life Science, Faculty of Life and Environmental Science, Prefectural University of Hiroshima \\ Nanatsuka, Shobara, 727-0023, Japan \\ *Corresponding author. Email: rori.muchamad17@gmail.com
}

\begin{abstract}
The allelopathic potential of various plants, including coffee species, has been studied. Although the allelopathic potential of coffee leaves, stems, and roots has been reported, there is no detailed information about coffee callus. Since this callus produces bioactive metabolites, we focused on investigating the allelopathic potential of Robusta coffee (Coffea canephora) callus as follows. The sandwich (SW) method, a small-scale bioassay using dried leaves of test plants and recipient lettuce seedlings, was adapted to identify the allelopathic activity of target coffee calli. Test samples were prepared as $10 \mathrm{mg}$ of dried calli under five drying conditions: oven drying at $40{ }^{\circ} \mathrm{C}, 60{ }^{\circ} \mathrm{C}, 80{ }^{\circ} \mathrm{C}$, silica gel drying, and freeze-drying. The appearance of each dried callus and chemical features of its water extract varied depending on drying conditions. However, all Robusta coffee calli showed a strong suppressive effect on the growth of hypocotyls and roots of lettuce seedlings. Based on this finding, we analyzed the endogenous level of caffeine (1,3,7-trimethylxanthine), a known allelochemical of coffee and tea plants, using HPLC. In this report, we discuss 1) technical points such as moisture content, drying method, and managing sample quality in the SW method for calli, and 2) the relationship between allelopathic potential and endogenous caffeine level of Robusta coffee calli.
\end{abstract}

Keywords: allelopathy, coffee callus, sandwich method

\section{INTRODUCTION}

Allelopathy is a phenomenon by which plants biochemically exert influence overgrowth, survival, or reproduction of target organisms. It can be direct or indirect, have beneficial or adverse effects, and affect a plant's own or another plant's growth through the release of biochemical(s) into the environment. It affects plant distribution, community formation, intercrop evolution, and biodiversity conservation, and as such is a topic of international interest [1]. The biochemicals produced are known as allelochemicals. To ensure sustainable agricultural development, it is important to exploit cultivation systems that take advantage of the stimulatory/inhibitory influence of allelopathic plants to regulate plant growth and development and to avoid allelopathic autotoxicity. Allelochemicals can potentially be used as growth regulators, herbicides, insecticides, and antimicrobial crop protection products [2].

Coffee is one of the most important commodities cultivated worldwide and has a great economic impact in many countries [3]. The most cultivated variety is Coffea arabica, which has several important cultivars and is responsible for $60 \%$ of world production [4]. Another important variety is C. canephora, otherwise known as
Robusta coffee. The allelopathic potential of various plants, including coffee commodities, has been studied. In previous research, aqueous extracts of leaves, stems, and roots of Coffea arabica significantly inhibited the seed germination and radicle growth of rye grass, lettuce, and fescue [5]. The allelopathic activity of coffee seed extract and powder was also reported by Paneva [6]. However, there is scant information about the allelopathic activity of coffee calli, especially that of Robusta coffee callus.

In this report, we focus on a small-scale bioassay named the sandwich (SW) method, originally established for investigating the allelopathic activitiy of dried leaves of test plants [7]. Allelopathic activity was determined by comparing the hypocotyl and radicle length of recipient lettuce seedlings grown in media with or without 10-50 mg of dried leaves for 3 days [8]. Although the scale of this bioassay is suitable to check allelopathic activity of target calli within a short time, there is no technical information for the SW method using coffee callus. The objectives of this study are 1) to discuss technical points, such as moisture content of samples, drying method, and management of sample quality for establishing the SW method for callus, and 2) to explore the relationship between allelopathic potential and endogenous caffeine level of Robusta coffee calli. 


\section{METHODS}

\section{a. Pre-measurement of moisture content}

We used a moisture analyzer (Ohaus MB45) to monitor the relative moisture content of Robusta coffee callus $(1 \mathrm{~g}$ fresh weight). The rate of water loss during linear drying at $60^{\circ} \mathrm{C}$ was measured. Fresh samples (10 leaves and 10 calli of several plants, see Table 1) were dried using an oven drier (EYELA Natural Oven NDO-450) at $60{ }^{\circ} \mathrm{C}$ for 8 hours to identify the variation of moisture content in samples.

\section{b. Comparison of drying conditions for sample preparation}

We used 4-week-old Robusta coffee calli from a regular maintenance subculture period (every 4 weeks) on modified MS medium containing $10 \square \mathrm{M}$ 2,4-D. Fresh samples were collected and dried using an oven drier (EYELA Natural Oven NDO-450) at 40,60 , and $80^{\circ} \mathrm{C}$, or dried using silica gel ( $5 \mathrm{~g}$ silica gel in a glass jar) or a freeze dryer (TAITEC DC-120). After 8 hours of drying, dried samples were tightly packed in plastic zip-bags and stored at room temperature until use. Water extracts were prepared as follows: briefly, $10 \mathrm{mg}$ dried sample was put into a 1.5 $\mathrm{ml}$ microcentrifuge tube and $300 \square 1$ distilled water was added. The sample was then processed for 20 minutes by

A

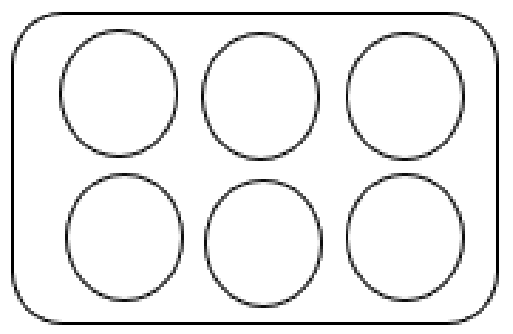

B

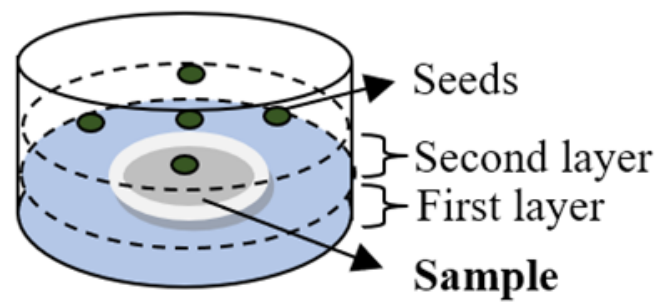

ultra-sonication without any mechanical mashing. The supernatant obtained was examined by spectrum scanning (240-500 nm) using a microplate reader system (Varioskan Flash, Thermo Scientific).

\section{c. The sandwich (SW) Method}

For the SW method bioassay, we referenced the original method by Fujii, et al [7] and added a modification. Briefly, we prepared agar growth medium for the the two outer layers of the sandwich using purified agar (SeaKem GTG Agarose, Cambrex Bio Science Rockland, Inc., Rockland ME, USA). After weighing agar powder $(0.5 \% \mathrm{w} / \mathrm{v})$, we added it and $100 \mathrm{ml}$ distilled water to a $200 \mathrm{ml}$ flask, then covered the flask with a plastic wrap. The agar solution was then heated using a microwave $1.5 \mathrm{~min}$ at $600 \mathrm{~W}$. After the solution boiled, we poured $5 \mathrm{ml}$ molten agar solution into an individual well of a six-well plate to set the first layer. After putting $10 \mathrm{mg}$ dried sample onto the first layer after setting, we then poured another $5 \mathrm{ml}$ of agar solution on top of the sample to set the second layer. Then, 5 lettuce seeds (Lactuca sativa L., Great Lakes 366) were vertically placed into each well (Figure 1). For the control, we used $10 \mathrm{ml}$ agar solution with 5 lettuce seeds on it. We covered the set sixwell plate with a plastic lid and appropriately labeled it. We then incubated the plate at $20^{\circ} \mathrm{C}$ in the dark.

Figure 1. The SW method: A. Six-well plate; B. Sequence of sandwich layer: (1, first agar layer (5 ml); 2 , dried sample (10 mg callus); 3, second agar layer (5 ml); 4, five lettuce seeds); C. Placement of lettuce seeds.

\section{d. Growth Measurement}

Length of hypocotyls and roots of germinated lettuce seeds were measured using Image $\mathrm{J}$ software after three days of incubation at $20{ }^{\circ} \mathrm{C}$ in the dark. The control consisted of seeds germinated in the absence of dried calli. Data were recorded as $\%$ growth of the control and averaged with standard error (SE).

\section{e. HPLC Analysis}

Robusta coffee callus (100 mg fresh weight) was extracted with $0.5 \mathrm{ml}$ distilled water $(0.2 \mathrm{w} / \mathrm{v})$ in a microcentrifuge tube, and the supernatant was subjected to reverse-phase HPLC (column, Cosmosil Packed Column 5C18-MS-II, 4.6 ID x $150 \mathrm{~mm}$ from Nacalai Tesque (Kyoto, Japan); column oven, $40{ }^{\circ} \mathrm{C}$; solvent, $20 \%$ methanol; flow rate, $0.6 \mathrm{ml} \mathrm{min}^{-1}$; detection, $270 \mathrm{~nm}$ ). Caffeine (MW 194.19, Wako Pure Chemical Industries, Ltd., Osaka, Japan) was used as the standard solution. Injection volume was set at $10 \mu \mathrm{l}$ using a MICROLITER ${ }^{\mathrm{TM}}$ syringe (Hamilton, Reno NV, USA).

\section{RESULTS AND DISCUSSION}

\section{a. Pre-measurement of moisture content}

Measuring moisture content is one of the most important ways to identify the uniformity of plant materials. First, we measured the behavior of water in a mass of target callus during a linear drying process. As shown in Figure 2, coffee callus showed a high uniformity in 3 replicate measurements within a short time as measured by moisture analyzer. The average of the final moisture content was $88 \%$ after 102 minutes of the drying process. Although variation (up to $\sim 5-10 \%$ ) is expected in measurements made by moisture analyzer, the average value will be a useful reference to define suitable drying conditions for calli of interest in further experiments. 


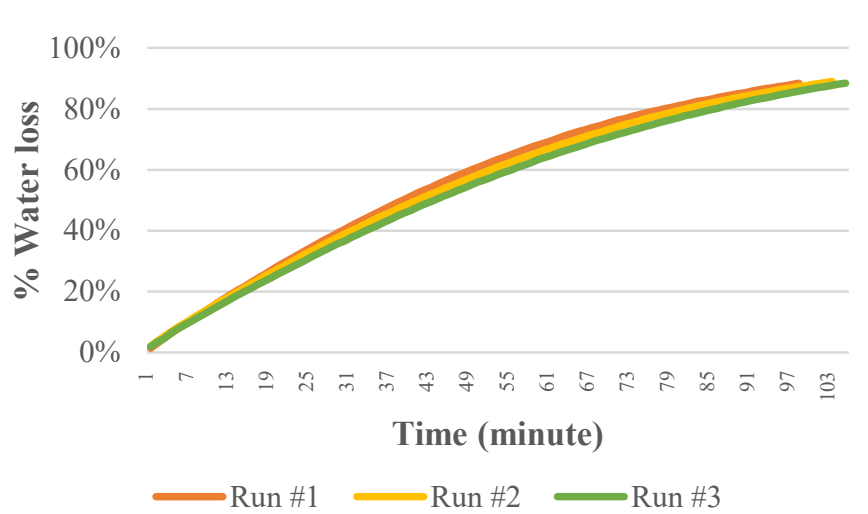

Figure 2. The behavior of water in a mass of coffee callus during a linear drying process at $60^{\circ} \mathrm{C}$.

Next, we investigated the variation of moisture content of leaves and calli from various plants. Fresh samples (10 leaves and 10 calli of several plants, see Table 1) were dried using an oven drier (EYELA Natural Oven NDO-450) at $60{ }^{\circ} \mathrm{C}$ for 8 hours according to the original SW method. When we used in vitro-grown leaves from 2 herbaceous plants (Houttuynia cordata and Nicotiana tabacum) and 2 woody plants (Coffea arabica and Populus alba), moisture contents varied in the range of $78.1 \%$ to $93.5 \%$. When we used field-grown leaves from 2 bamboo plants (Bambusa oldhamii and Dendrocalams latiflorus) and 4 woody plants (Akebia quinata, A. trifoliate, Gardenia jasminoides, and Populus sp.), the variation of moisture contents had a wider range, from $56.2 \%$ to $76.2 \%$. Based on these results, we suggest that the value of the moisture content of target leaves should be carefully discussed before their use as experimental materials for evaluating bioactivities. On the other hand, all the 10 calli tested showed a high degree of similarity, with most having more than $95 \%$ moisture content. These values were the same as the moisture content preliminarily measured with the moisture analyzer (see Figure 2). Although the moisture content of each callus did not vary in this experiment, we must note a few key points.

Table 1. Comparison of moisture content of 10 different plant leaves (A) and 10 different callus strains (B).

A : Plant leaves

\begin{tabular}{|c|c|c|c|}
\hline Category & Scientific name & $\begin{array}{l}\text { Common } \\
\text { name }\end{array}$ & $\begin{array}{c}\text { Moisture } \\
\text { content (\%) }\end{array}$ \\
\hline \multirow{4}{*}{ In vitro } & Nicotiana tabacum & Tobacco & 93.5 \\
\hline & Houttuynia cordata & Dokudami & 89.7 \\
\hline & Populus alba & Poplar & 85.6 \\
\hline & Coffea arabica & Arabica coffee & 78.1 \\
\hline \multirow{6}{*}{ Field } & Akebia trifoliata & 3Leaves Akebi & 76.2 \\
\hline & Populus sp. & Poplar (Field) & 74.7 \\
\hline & Gardenia jasminoides & Cape jasmine & 66.7 \\
\hline & Bambusa oldhamii & Green-bamboo & 59.6 \\
\hline & $\begin{array}{c}\text { Dendrocalamus } \\
\text { latiflorus }\end{array}$ & $\begin{array}{c}\text { Ma-bamboo } \\
\text { (Giant bamboo) }\end{array}$ & 59.1 \\
\hline & Akebia quinata & 5Leaves Akebi & 56.2 \\
\hline
\end{tabular}

B : Callus strains

\begin{tabular}{|c|c|c|c|}
\hline Category & Scientific name & $\begin{array}{l}\text { Common } \\
\text { name }\end{array}$ & $\begin{array}{c}\text { Moisture } \\
\text { content }(\%)\end{array}$ \\
\hline \multirow{4}{*}{ Tree } & $\begin{array}{c}\text { Chamaecyparis } \\
\text { obtusa }\end{array}$ & Hinoki & 97 \\
\hline & Sonneratia ovata & Mangrove & 95.5 \\
\hline & Derris indica & Pongame oil tree & 95.1 \\
\hline & Coffea canephora & Robusta coffee & 94.3 \\
\hline \multirow{3}{*}{ Fruit } & Prunus persica & Peach/momo & 96.9 \\
\hline & Punica granatum & Zakuro & 95.3 \\
\hline & Ficus carica L. & Ichijiku & 91.3 \\
\hline \multirow{3}{*}{ Bamboo } & $\begin{array}{l}\text { Phyllostachys nigra } \\
\text { Munro var. Henonis }\end{array}$ & Hachiku & 96.9 \\
\hline & $\begin{array}{c}\text { Bambusa multiplex } \\
\text { Raeush }\end{array}$ & Houraichiku & 96.4 \\
\hline & $\begin{array}{c}\text { Dendrocalamus } \\
\text { gigenteus Munro }\end{array}$ & Kyochiku & 96 \\
\hline
\end{tabular}

When we perform a maintenance culture of a target callus, a series of growth stages can be seen. These stages are: 1) lag phase, in which metabolite mobilization starts and synthesis of proteins and specific metabolites occurs without cell multiplication; 2) exponential phase, in which cell division reaches the maximum; 3 ) linear phase, in which cell division is reduce; 4) deceleration phase, in which cell division decreases and cell expansion occurs (at this point, we have to transfer the callus to a new culture medium due to the reduction of nutrients, agar dryness and accumulation of toxic substances); 5) stationary phase, in which no cell division or weight increase occurs, but the secondary metabolite accumulation sometimes increases; and 6) decline phase, in which weight is lost due to cellular death [9][10][11]. It is important to carefully define the culture period and growth stages of calli before using them experimentally.

\section{b. Comparison of drying condition for sample preparation}

In order to optimize the drying process for callus samples, we tested 3 oven drying conditions: 40,60 , and $80^{\circ} \mathrm{C}$. Non-heating conditions, both silica gel drying and freeze drying, were also examined to minimize damage to the sample and its components. Figure 3 shows the difference in percent water loss from each sample after 8 hours. With the exception of the silica gel drying condition, samples were highly or fully dried. Oven drying at $80{ }^{\circ} \mathrm{C}$ and freeze drying show the highest percent of water reduction, reaching $96 \%$ of fresh weight. Oven drying at $60{ }^{\circ} \mathrm{C}$ was slightly less effective, with samples achieving $94 \%$ water reduction, and oven drying at $40{ }^{\circ} \mathrm{C}$ produced $89 \%$ water reduction. Silica gel drying shows the weakest ability to reduce water in the sample during the drying process (46\% water reduction). It was expected that the relative concentration of endogeneous chemicals per unit weight of the callus would be $\sim 2-10$ times higher than that of the original sample. As shown in Figure 4, it was recognized that color and texture of the samples varied depending on the drying process. 


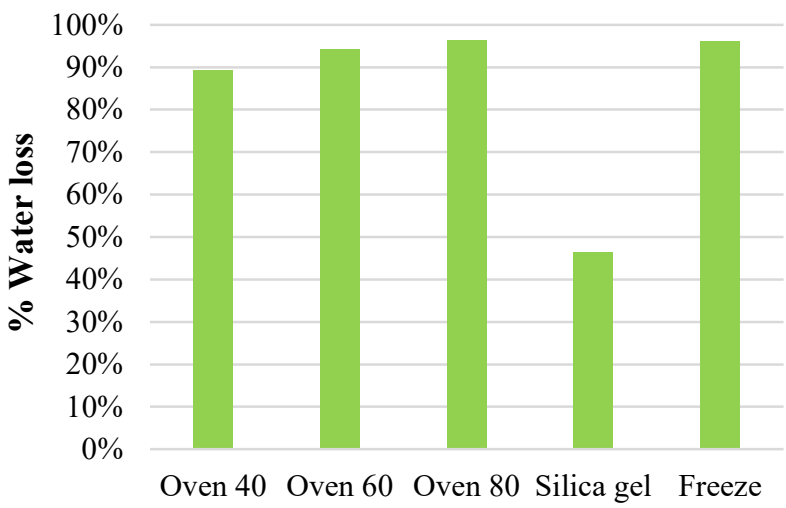

Sample drying condition

Figure 3. Water loss percentage in different drying processes after 8 hours. One $g$ fresh weight of coffee callus was measured in each condition. Note: freeze drying takes 24 hours.

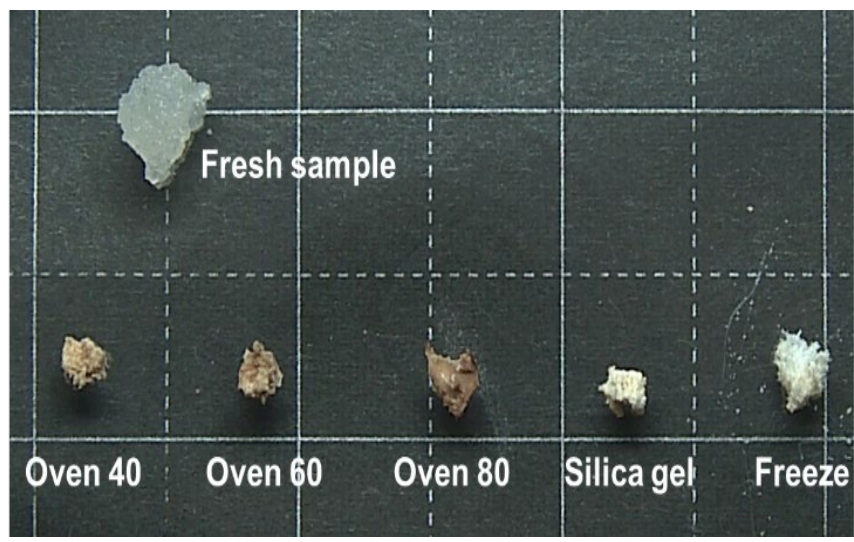

Figure 4. Characteristics of dried callus tissues in the different drying processes. Grid indicates $1 \mathrm{~cm}$.

When oven-dried $\left(40-80{ }^{\circ} \mathrm{C}\right)$, callus tissue gradually turned brownish in color, especially at higher temperatures. The texture also varied from crunchy to hard, tracking the color changes observed. In non-heating conditions, the color of callus tissues remained whitish under both conditons. However, a texture difference could be seen between the silica gel-dried sample and the freeze-dried sample. The former was crunchy on the outer surface but retained moisture in the middle, while the latter became crumbly in texture. We then confirmed the leaching efficiency of metabolites from dried calli using the water extraction method described in the Methods section.

Since this extraction method is a non-destructive process, it is expected to be a simulative environment in the SW method bioassay. The supernatants were examined by spectrum scanning (240-500 nm) using a microplate reader system (See Figure 5). Figure 5A shows profiles of the UV-vis absorption spectrum of oven-dried calli. The spectra of oven 40 and $60{ }^{\circ} \mathrm{C}$ conditions overlapped considerably, but the spectrum of the oven $80{ }^{\circ} \mathrm{C}$ condition showed a weak absorbance pattern. Figure 5B shows a clear difference between the silica-drying and freeze-drying processes. The spectrum of silica drying had a similar pattern to that of oven 40 and $60{ }^{\circ} \mathrm{C}$ conditions. As the overall estimetion,
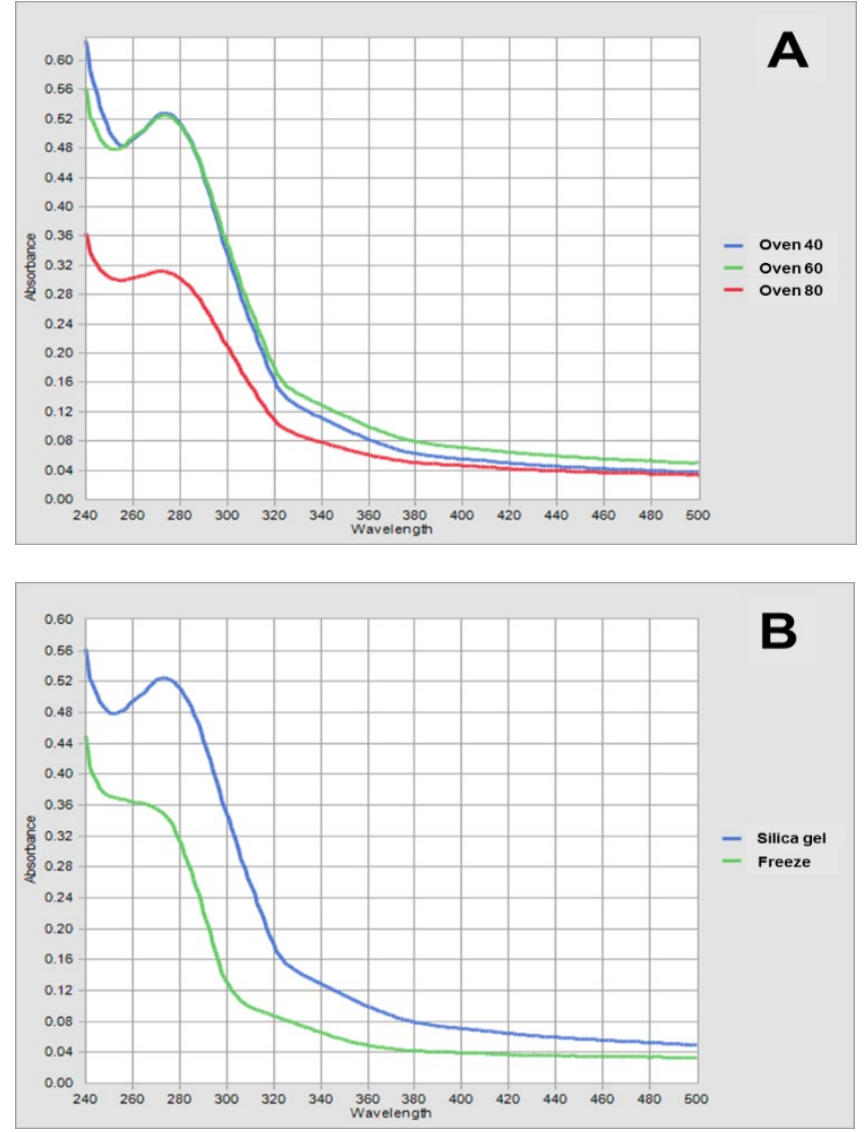

Figure 5. The profiles of UV-vis absorption spectrum of A. oven-dried samples and B. non-heating dried samples.

\section{c. The SW Method}

All dried calli were evaluated using the SW method to determine allelopathic activity. Strong inhibitory effects on the growth of lettuce seeds could be seen. As shown in Figure 6, we captured the germination pattern using a digital camera and measured the length of hypocotyls and roots in each sprout using Image J software.
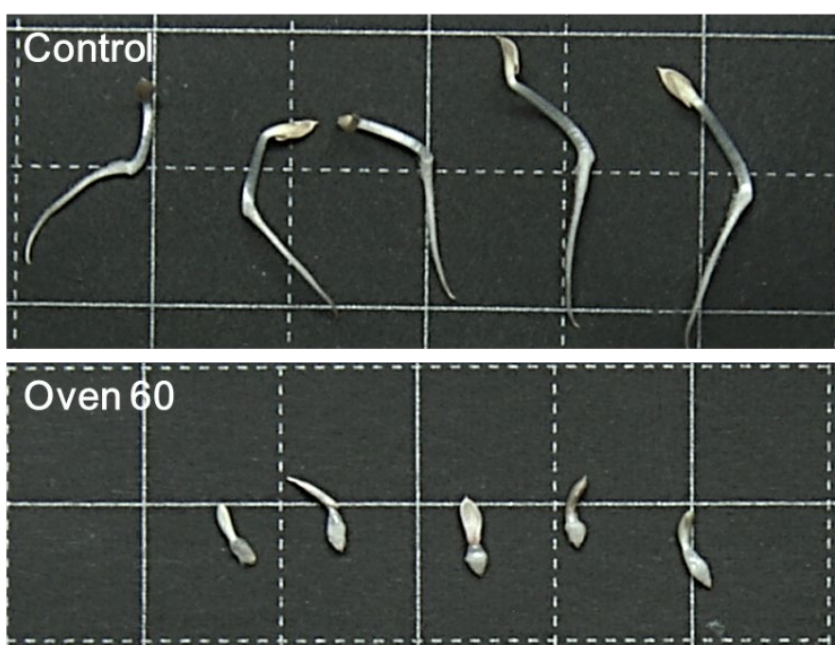

Figure 6. Images of germinated lettuce seeds after three days of incubation at $20^{\circ} \mathrm{C}$ in the dark. Grid indicates $1 \mathrm{~cm}$. 


\section{d. Growth Measurement}

The percent lettuce seed growth is summarized in Figure 7. Leachates from dried Robusta coffee calli were considered strong inhibitory factor(s) since all the oven-dried samples and freeze-dried samples showed more than $85 \%$ inhibition of hypocotyl and root elongation. On the other hand, the sample from silica gel-drying showed weaker inhibition (only $40 \%$ inhibition to root growth). This might be due to a lower waterloss percentage (see Figure 3).

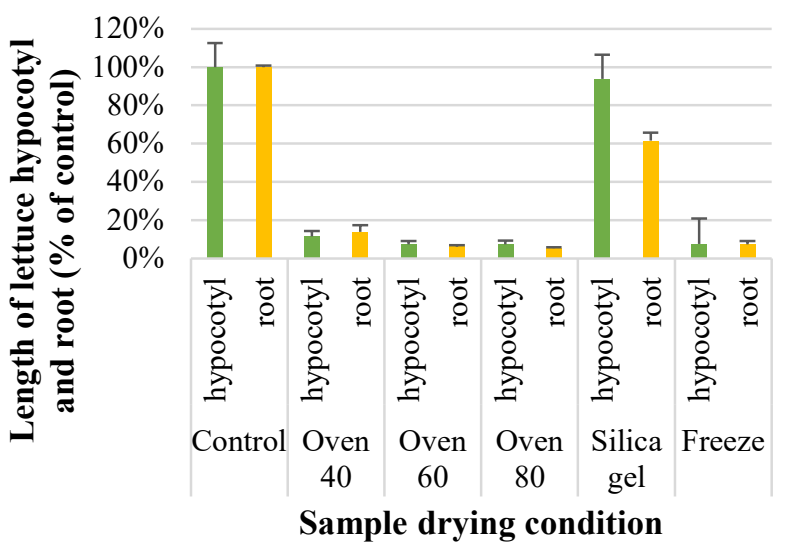

Figure 7. Length of lettuce hypocotyl and root (\% of control) after three days of incubation at $20^{\circ} \mathrm{C}$ in the dark.

Averages with SE $(\mathrm{N}=5)$.

Chou and Waller [5] have suggested that the phytotoxins present in coffee tissue are caffeine, theobromine, theophylline, paraxanthine, scopoletin, and caffeic, chlorogenic, vanillic, ferulic, p-coumaric, and p-hydroxybenzoic acids. Caffeine (1,3,7-trimethylxanthine) and its derivatives are thought to be strong allelochemicals [12][13][14]. Sasamoto, et al. reported that the effect of caffeine and theophylline at $1000 \mu \mathrm{M}$ is to completely inhibit the proliferation of lettuce cells derived from protoplast culture [15]. We carried out HPLC analysis to measure the endogenous caffeine level of Robusta coffee calli, described in the next section.

\section{e. HPLC Analysis}

Robusta coffee callus showed more than $85 \%$ inhibition to elongation of hypocotyls and roots. To clarify the endogenous caffeine level, we analyzed the water extract of 4week-old Robusta coffee callus via HPLC. The endogenous caffeine level was averaged with standard error, (e.g. $22.3 \pm 4.6$ $\mathrm{nmol} / 100 \mathrm{mg}$ fresh weight) from 5 independent measurements. Several unknown metabolites were also detectable at $270 \mathrm{~nm}$ (data not shown)

\section{CONCLUSION}

1) The SW method is applicable to investigate allelochemicals in target calli. 2) Several technical points for optimizing the SW method are suggested. 3) Further detailed allelochemical analysis should be carried out using HPLC.

\section{ACKNOWLEDGMENT}

The author (MIA) acknowledges the Ministry of Education, Culture, Sports, Science, and Technology (MEXT) Scholarship for funding while studying in Japan. The author also expresses gratitude to the Prefectural University of Hiroshima for providing me with financial support to the international conference (IC-FANRes 2019, Ternate, Indonesia).

\section{REFERENCES}

[1] Zhang, KaiMei, Shi Lei and Li ZhenYu. "Fern Allelopathy and Its Impact on Biodiversity". Biodiversity Science, 12: 466- 471. 2004.

[2] Cheng Fang and Cheng Zhihui. "Research Progress on the use of Plant Allelopathy In Agriculture and the Physiological and Ecological Mechanisms of Allelopathy". Review article. Front. Plant Sci, College of Horticulture, Yangling, China. 2015.

[3] FAOSTAT. "FAOSTAT Data". Available at: http://www.fao.org/faostat/en/\#data/QC/visualize. 2014.

[4] van der Vossen, H., Bertrand, B., and Charrier, A. "Next generation variety development for sustainable production of arabica coffee (Coffea arabica L.): a review". Euphytica 204, 243-256. doi: 10.1007/s10681015-1398-z.2015.

[5] Chou CH, Waller GR. "Possible allelopathic constituents of Coffea arabica". Journal of Chemical Ecology, 6, 643-654.1980.

[6] Peneva, A. "Allelopathic effect of seed extracts and powder of coffee (Coffea arabica L.) on common cocklebur (Xanthium strumarium L.)”. Bulg. J. Agric. Sci.,13: 205-211.2007.

[7] Fujii, Y., Pavez, S.S., Pavez, M.M., Ohmae, Y. and Iida, O. "Screening of 239 Medicinal Plant Species for Allelopathic Activity using the Sandwich Method". Weed Biology and Management,3,233-241. https://doi.org/10.1046/j. 1444-6162.2003.00111.x. 2003.

[8] Ogita,S., Sasamoto, H. “ In Vitro Bioassay of Allelopathy in Four Bamboo Species; Bambusa multiplex, Phyllostachys bambusoides, P. nigra, Sasa kurilensis, Using Sandwich Method and Protoplast CoCulture Method with Digital Image Analysis. American Journal of Plant Science,B,1699-1710. http://www.scrip.org/journal.ajps. 2017.

[9] Castro, A. H. F. et al. Curva de crescimento, atividade da fenilalanina amônia-liase e teores de fenóis e taninos totais em calos de Stryphnodendron adstringens (Mart.) Coville (Fabaceae Mimosoideae). Plant Cell Culture \& Micropropagation, v. 4, n. 2, p. 99-104, 2008.

[10] Nogueira, R. C. et al. Curva de crescimento e análises bioquímicas de calos de murici-pequeno (Byrsonima intermedia A. Juss.). Revista Brasileira de Plantas Medicinais, v. 10, n. 1, p. 44-48, 2008.

[11] Santos, M. R. A; Ferreira, M. G. R.; Sarubo, V. "Determination of callus growth curve in conilon coffee". Revista Caatinga, v. 23, n. 1, p. 133-136, 2010.

[12] Frischknecht, P. M., J. Ulmer-Dufek and T.W. Bauman. "Purine alkaloid formation in buds and developing leaflets of Coffea arabica: expression of an optimal defense strategy". Phytochemistry, 3: 613-616. 1985.

[13] Vitoria, A. P. and P. Mazzafera. Caffeine degradation in leaves and fruits of Coffea arabica and C. dewevrei, Pesquisa Agropecuaria brasileira, 33: 1957-1961. 1998.

[14] Hesse, M. "Alkaloids: nature's curse or blessing". Wiley-VCH, Weinheim, Germany, xii 413 pp. 2002.

[15] Sasamoto, H., Fujii, Y., and Ashihara, H. "Effect of purine alkaloids on the proliferation of lettuce cells derived from protoplasts". NPC Vol. 10, No. 5751 754. 2015. 